\title{
Lignan contents of Dutch plant foods: a database including lariciresinol, pinoresinol, secoisolariciresinol and matairesinol
}

\author{
Ivon E. J. Milder ${ }^{1,2}$, Ilja C. W. Arts ${ }^{1}$, Betty van de Putte ${ }^{1}$, Dini P. Venema ${ }^{1}$ and Peter C. H. Hollman ${ }^{1}$ * \\ ${ }^{1}$ RIKILT-Institute of Food Safety, Wageningen University and Research Centre, PO Box 230, 6700 AE Wageningen, The Netherlands \\ ${ }^{2}$ Centre for Nutrition and Health, National Institute for Public Health and the Environment, PO Box 1, 3720 BA Bilthoven, \\ The Netherlands
}

(Received 7 July 2004 - Revised 1 November 2004 - Accepted 9 November 2004)

\begin{abstract}
Enterolignans (enterodiol and enterolactone) can potentially reduce the risk of certain cancers and cardiovascular diseases. Enterolignans are formed by the intestinal microflora after the consumption of plant lignans. Until recently, only secoisolariciresinol and matairesinol were considered enterolignan precursors, but now several new precursors have been identified, of which lariciresinol and pinoresinol have a high degree of conversion. Quantitative data on the contents in foods of these new enterolignan precursors are not available. Thus, the aim of this study was to compile a lignan database including all four major enterolignan precursors. Liquid chromatography-tandem mass spectrometry was used to quantify lariciresinol, pinoresinol, secoisolariciresinol and matairesinol in eightythree solid foods and twenty-six beverages commonly consumed in The Netherlands. The richest source of lignans was flaxseed (301 $129 \mu \mathrm{g} / 100 \mathrm{~g})$, which contained mainly secoisolariciresinol. Also, lignan concentrations in sesame seeds $(29331 \mu \mathrm{g} / 100 \mathrm{~g}$, mainly pinoresinol and lariciresinol) were relatively high. For grain products, which are known to be important sources of lignan, lignan concentrations ranged from 7 to $764 \mu \mathrm{g} / 100 \mathrm{~g}$. However, many vegetables and fruits had similar concentrations, because of the contribution of lariciresinol and pinoresinol. Brassica vegetables contained unexpectedly high levels of lignans $(185-2321 \mu \mathrm{g} / 100 \mathrm{~g}$ ), mainly pinoresinol and lariciresinol. Lignan levels in beverages varied from 0 (cola) to $91 \mu \mathrm{g} / 100 \mathrm{ml}$ (red wine). Only four of the 109 foods did not contain a measurable amount of lignans, and in most cases the amount of lariciresinol and pinoresinol was larger than that of secoisolariciresinol and matairesinol. Thus, available databases largely underestimate the amount of enterolignan precursors in foods.
\end{abstract}

Lignans: Phytoestrogens: Food composition: Secoisolariciresinol: Matairesinol: Pinoresinol: Lariciresinol

Lignans are diphenolic compounds that are widely distributed in the plant kingdom. A large variety of plant lignans exist, but only a few of them are converted into the 'enterolignans' enterodiol and enterolactone by the intestinal microflora. Enterolignans are absorbed into the human body.

Until recently, only secoisolariciresinol and matairesinol were seen as enterolignan precursors, but new precursors have recently been identified, of which lariciresinol and pinoresinol have a high degree of conversion (Heinonen et al. 2001). Lignans possess several biological activities, such as antioxidant and (anti)oestrogenic properties, and may thus reduce the risk of certain cancers as well as cardiovascular diseases (Adlercreutz et al. 1992; Adlercreutz \& Mazur, 1997; Raffaelli et al. 2002; Arts \& Hollman, 2005).

Secoisolariciresinol and matairesinol have been quantified in a large number of plant foods. Flaxseed (linseed) is the richest known source of these lignans. Other sources are grains, seeds, vegetables, fruits and beverages (Mazur, 1998; Mazur \& Adlercreutz, 1998; Horn-Ross et al. 2000; Meagher \& Beecher, 2000). These data have been incorporated into several phytoestrogen databases (Horn-Ross et al. 2000; Keinan Boker et al. 2002; Valsta et al. 2003). Until now, data on the lariciresinol and pinoresinol contents of foods were not available.

A number of epidemiological studies on the associations between enterolignan concentrations in biological fluids or the intake of plant lignans and chronic disease risk has so far been conducted (reviewed by Arts \& Hollman, 2005). In case-control studies (Ingram et al. 1997; Pietinen et al. 2001; Dai et al. 2002), but not in prospective studies (Den Tonkelaar et al. 2001; Hulten et al. 2002; Grace et al. 2004), inverse associations have been found between plasma or urinary lignans and breast cancer risk. For cardiovascular diseases, inverse associations with serum lignans were reported in two Finnish studies (Vanharanta et al. 1999, 2003). In addition, studies in which the relation between the dietary intake of secoisolariciresinol and matairesinol and cancer risk was studied gave conflicting results. Protective associations were reported for breast (McCann et al. 2002), ovarian (McCann et al. 2003), endometrial (Horn-Ross et al. 2003) and thyroid (Horn-Ross et al. 2002a) cancer. In one study, a decreased risk of breast cancer was found only for high intakes of matairesinol, but not for secoisolariciresinol or secoisolariciresinol plus matairesinol (Linseisen et al. 2004). In two other studies, increased breast cancer risks were found with a high intake of secoisolariciresinol and matairesinol (Horn-Ross et al. 2001; 2002b).

To further evaluate the health effects of lignan intake, it is essential that the newly discovered enterolignan precursors are included. Thus, the aim of the present study was to compile a comprehensive database including all four major enterolignan 
precursors: lariciresinol, pinoresinol, secoisolariciresinol and matairesinol. Lignans were quantified in 109 plant foods commonly consumed in the Netherlands, including eighty-three solid foods and twenty-six beverages. Additionally, we studied the effect of cooking on the lignan content of a few vegetables.

\section{Materials and methods}

\section{Selection of foods}

Plant foods were selected for analysis based on data from the Dutch National Food Consumption Survey conducted in 1997-98. This survey was carried out among a sample of households representative of the Dutch population. Two-day dietary records were collected for 6250 persons aged 1-97 years (Hulshof \& Van Staveren, 1991; Voedingscentrum, 1998).

In general, plant foods with an average consumption of over $3 \mathrm{~g}$ per person per day were selected. Mixed dishes (e.g. apple pie, pizza) were not selected for analysis since their lignan content can be calculated from their ingredients using standard recipes. For fruits, a limit of $1 \mathrm{~g}$ per person per day was used. Because of their relatively high consumption, a limit of $10 \mathrm{~g}$ per person per day was used for beverages. Waters and soft drinks (except cola) were disregarded. Apple juice was not analysed because the lignan content of apples was very low (see below). Vegetable oils and fats with an average consumption of over $0.5 \mathrm{~g}$ per person per day were also added. Using this method, forty-two plant foods were selected. Some important plant foods, for example leek and sweet pepper, were missed because they are ingredients of a large number of foods but are not consumed in large quantities as such. We therefore also used data on the consumption of primary agricultural products. These data were derived from the Food Consumption Survey data using the Conversion Model for Primary Agricultural Products developed at RIKILT (Van Dooren-Flipsen et al. 1995). Four extra fruits and eleven extra vegetables were selected, using the same criteria as before. In addition, foods that were high in lignans according to data in the literature, but did not meet the aforementioned consumption criteria, were also selected (e.g. seeds, olives, cashew nuts). Tofu, soya milk and legumes were added since they might be important plant foods for specific population groups (e.g. vegetarians).

\section{Sample collection}

Foods were purchased in the form (fresh, canned, in jars, frozen) that was most commonly consumed according to the Food Consumption Survey. In order to enhance the representation of the food samples, products were bought at three different locations (fresh products) or from three major brands (processed foods), and composite samples were assembled. In addition, for fresh products, a minimum of $0.5 \mathrm{~kg}$ or 3 units was sampled at each location: an outlet of a nationwide supermarket chain, a local grocery and an open-air street market. The proportion in the composite samples reflected the sales of each food group at each location. For vegetables, the supermarket accounted for $78 \%$, the grocery for $11 \%$ and the open-air market for $11 \%$; for fruits, these values were $70 \%, 12 \%$ and $18 \%$, respectively. Potatoes were bought at two supermarkets (each contributing $45 \%$ ) and a local grocery store (contributing $10 \%$ ). Breads were also bought at two supermarkets (each contributing $37.5 \%$ ) and a local bakery (contributing $25 \%$ ). For processed foods, composite samples were assembled by mixing the three brands in equal proportions.

\section{Sample preparation}

Non-edible parts were removed from the fruit and vegetables. Vegetables were not prepared further since cooking or frying was considered to have only a small effect on lignan content. This assumption was based on the fact that the first step in the lignan analysis consisted of the alkaline extraction for $1 \mathrm{~h}$ at $60^{\circ} \mathrm{C}$, which did not lead to a considerable loss of lignans (Milder et al. 2004). However, we checked this assumption, because during cooking and frying temperatures are higher and lignans might also be lost by leaching. A few vegetables were therefore analysed both raw and prepared according to standard recipes. Lignans in potatoes, rice and macaroni were determined in the prepared product according to standard recipes or the instructions on the packaging.

Composites of solid foods were either directly chopped under liquid $\mathrm{N}_{2}$ or cut into smaller pieces prior to freezing in liquid $\mathrm{N}_{2}$, and stored at $-20^{\circ} \mathrm{C}$ until freeze-drying was started within 1 month. After freeze-drying, samples were ground to a powder using a Tecator Knifetec 1095 sample mill (Rose Scientific Ltd, Edmonton, Canada). Dry products, which did not require freeze-drying, such as seeds, muesli and wheat (meal and wholegrain), were ground before preparing the composite samples. Fruits were frozen in liquid $\mathrm{N}_{2}$ before grinding. All composites of solid foods were stored at $-20^{\circ} \mathrm{C}$ until analysis.

Beverages were collected within $48 \mathrm{~h}$ of analysis. Composites were prepared immediately before analysis by mixing three major brands in equal proportions. Beer was degassed in an ultrasonic bath at room temperature. Since alcohol might influence the activity of the enzyme used in the analytical method, beer and wine were analysed both with and without the evaporation of alcohol (using a Zymark Turbo vap LV Evaporator; Zymark Corp., Hopkinton, MA, USA) at $60^{\circ} \mathrm{C}$, under a mild $\mathrm{N}_{2}$ flow $(5-10 \mathrm{psi})$. Since the evaporation of alcohol produced no substantial changes in lignan concentrations, and increased the variation between duplicate samples, the lignan values of the analyses without the evaporation of alcohol are presented here. Tea infusion was prepared by placing one tea bag ( 1 or $2 \mathrm{~g}$ ) in boiling tap water $(100 \mathrm{ml} / \mathrm{g}$ tea leaves). After $5 \mathrm{~min}$, the tea bag was stirred a few times, after which it was removed. Coffee was prepared according to Dutch custom in a coffee-maker with paper filter: a volume of $275 \mathrm{ml}$ boiling water was dripped on $14 \mathrm{~g}$ ground coffee. Chocolate milk was diluted ten times with sodium acetate buffer $(0.05 \mathrm{M}, \mathrm{pH} 5.0)$, in order to avoid gelling during the ether extraction.

\section{Standards}

Pure standards of secoisolariciresinol (purity approximately $92 \%$ ) and matairesinol (purity $>98 \%$ ) were obtained from Plantech (Reading, England). Lariciresinol isolated from the wood of Abies sachalinensis and pinoresinol isolated from Euconmia ulmoides oliv. bark were kindly provided by $\mathrm{Dr}$ Ozawa (Rakuno Gakuen University, Japan), Dr Deyama (Yomeishu Seizo Co. Ltd, Japan) and Dr Nishibe (University of Hokkaido, Japan). Internal standards of secoisolariciresinol- $d_{8}$ and matairesinol- $d_{6}$ were kindly provided by $\operatorname{Dr} K$. Wähälä (University of Helsinki, Finland). 


\section{Analytical method}

The four major enterolignan precursors lariciresinol, pinoresinol, secoisolariciresinol and matairesinol were measured in each food sample using a liquid chromatography-tandem mass spectrometry method previously described in detail (Milder et al. 2004). In brief, lignans were extracted from solid foods with methanol-water $(70: 30 \mathrm{v} / \mathrm{v})$ containing $0.3 \mathrm{M}$ $\mathrm{NaOH}$ at $60^{\circ} \mathrm{C}$ for $1 \mathrm{~h}$. After neutralising and centrifuging, an aliquot of the supernatant was transferred to a test-tube, and methanol was evaporated under a mild $\mathrm{N}_{2}$ flow. The extract obtained, or pure beverage, was incubated overnight with Helix pomatia $\beta$-glucuronidase/sulphatase in sodium acetate buffer $(0.05 \mathrm{M}, \mathrm{pH} 5.0)$ at $37^{\circ} \mathrm{C}$. After enzymatic hydrolysis, samples were extracted twice with diethyl ether. The organic phases were combined, evaporated to dryness and dissolved in methanol-water $(30: 70 \mathrm{v} / \mathrm{v})$. Internal deuterated standards were added, and samples were subjected to liquid chromatography-tandem mass spectrometry analysis, with atmospheric pressure chemical ionization in the negative-ion mode. Multiple reaction monitoring was performed with the following precursor/product combinations: lariciresinol (359.1/329.1), and secoisolariciresinol $(361 \cdot 1 / 165 \cdot 1)$ with internal standard secoisolariciresinol- $d_{8}$ (369.2/168.3), and pinoresinol (357.1/ 151.2) and matairesinol (357.1/83.1) with internal standard matairesinol- $d_{6}(363 \cdot 2 / 83 \cdot 1)$.

\section{Analytical quality control}

Control samples were included at the beginning and end of each series of analyses. Single batches of freeze-dried and ground broccoli and wholegrain wheat bread were used as control samples for solid foods. These samples had been stored at $-20^{\circ} \mathrm{C}$. Black tea infusion was used as a control sample for beverages. One batch of tea leaves was prepared by passing black tea (from tea bags) through two sieves of 0.8 and $0.355 \mathrm{~mm}$. The middle fraction was stored at room temperature for use as a control product. For each series of analyses, a fresh tea infusion was prepared by adding $100 \mathrm{ml}$ boiling tap water to $1 \mathrm{~g}$ tea leaves. After $5 \mathrm{~min}$, this was stirred, and $50 \mathrm{ml}$ was filtered through a $1.2 \mu \mathrm{m}$ Acrodisc filter (Gelman Sciences, Ann Arbor, MI, USA).

Calibration standards of $20,100,200,600$ and $1000 \mathrm{ng} / \mathrm{ml}$ of each lignan, with $200 \mathrm{ng} / \mathrm{ml}$ of deuterated standards, were injected three times, at the beginning, middle and end of each series of analyses. If the lignan values in the sample extracts exceeded $1000 \mathrm{ng} / \mathrm{ml}$, the sample was reanalysed after diluting the alkaline extract. For solid foods, the limit of detection (signal to noise ratio of 3) for lariciresinol was $4 \mu \mathrm{g} / 100 \mathrm{~g}$ dry weight, for pinoresinol $10 \mu \mathrm{g} / 100 \mathrm{~g}$ dry weight, and for secoisolariciresinol and matairesinol $6 \mu \mathrm{g} / 100 \mathrm{~g}$ dry weight. Depending on the moisture content of the food, this corresponded to $0 \cdot 2-10 \cdot 0 \mu \mathrm{g} / 100 \mathrm{~g}$ fresh weight. Detection limits for beverages were for lariciresinol and matairesinol $0.2 \mu \mathrm{g} /$ $100 \mathrm{ml}$, for pinoresinol $0.4 \mu \mathrm{g} / 100 \mathrm{ml}$, and for matairesinol $0.3 \mu \mathrm{g} / 100 \mathrm{ml}$. The within-run reproducibility for the analysis of the control samples was $6-21 \%$ and the between-run reproducibility 6-33\% (Milder et al. 2004). All samples were analysed in duplicate. If differences between the duplicates were more than $20 \%$, the analysis was repeated and the mean values of the two duplicate analyses were used.

\section{Results and discussion}

We found that almost all of the selected plant foods contained lignans (Tables 1 and 2). Only four out of the 109 products did not contain a measurable amount of lignans. The amount of lignans in plant foods varied widely, from 0 to $301000 \mu \mathrm{g} / 100 \mathrm{~g}$ fresh weight. Interestingly, in almost all products the newly discovered enterolignan precursors lariciresinol and pinoresinol were found in higher concentrations than the well-known precursors secoisolariciresinol and matairesinol. Thus, databases with only secoisolariciresinol and matairesinol largely underestimate the amount of enterolignan precursors. Besides flaxseed, grain products have been the main focus of lignan research. However, our results show that the lignan contents of many of the vegetables and fruits are similar to those of the grain products when lariciresinol and pinoresinol are also included.

Any comparison of food composition data from various sources is complicated by geographical differences in foods, such as plant variety, growth conditions and food processing. Additional differences may result from variations in the ripeness or season of collection of the sampled foods. Keeping this in mind, we compared our results primarily with lignan data reported by Mazur et al. $(1998 a, b)$ and Horn-Ross et al. (2000) since these were the most comprehensive sources.

Mazur and co-workers quantified secoisolariciresinol and matairesinol in a variety of Finnish foods with isotope dilution gas chromatography-mass spectrometry (Mazur et al. 1996), and these data have been published in several original and review publications (Adlercreutz \& Mazur, 1997; Mazur, 1998; Mazur \& Adlercreutz, 1998, 2000; Mazur et al. 1998a, b). However, as they report lignan values only on a dry weight basis, it is not possible to compare our lignan values directly with these results.

Recently, some additional lignan values were published on the occasion of the construction of a Finnish phytoestrogen database (Valsta et al. 2003). Since these data were expressed on a fresh weight basis, we used these data in preference for comparison. In general, our results for secoisolariciresinol and matairesinol are in agreement with or slightly lower than those published by Mazur et al., although larger differences exist for a few products, which will be discussed below. Horn-Ross and co-workers measured secoisolariciresinol and matairesinol in foods from California (Horn-Ross et al. 2000). They also used an HPLCmass spectrometry method for quantification. In general, our data for secoisolariciresinol are in agreement with or slightly higher than their results. However, since their limit of detection is relatively high $(25 \mu \mathrm{g} / 100 \mathrm{~g})$ compared with ours $(0 \cdot 2-10 \cdot 0 \mu \mathrm{g} / 100 \mathrm{~g})$, they found lignan concentrations to be below the detection limit in many products.

The lignan contents reported in this paper are measured after alkaline extraction from solid foods. Under alkaline conditions, ester-linked oligomers of secoisolariciresinol in flax are hydrolysed to give the lignan monomer (Ford et al. 2001). Alkaline hydrolysis increased the lignan yield of flax about five-fold, but lignan yields from broccoli and bread were also substantially increased (Milder et al. 2004). Although we only tested these products, this indicates that ester-linked lignans also occur in other foods besides flax. In addition, because we showed that our carefully optimised alkaline extraction method gave reproducible results (Milder et al. 2004), we decided to use this method for our food analyses. 
Table 1. Lignan content ( $\mu \mathrm{g} / 100 \mathrm{~g}$ fresh edible weight) of solid foods

(Mean of duplicate analyses of composite samples)

\begin{tabular}{|c|c|c|c|c|c|c|c|}
\hline Product & Type, processing & Moisture content $(\%)^{\star}$ & LARI & PINO & SECO & MAT & Total \\
\hline \multicolumn{8}{|l|}{ Oilseeds and nuts } \\
\hline Flaxseed (Linum usitatíssimum L.) & & $-\dagger$ & 3041 & 3324 & 294210 & 553 & 301129 \\
\hline Sunflower seed (Helianthus annuus L.) & & - & 671 & 167 & 53 & 0 & 891 \\
\hline Cashew (Anacardium occidentale L.) & & - & 496 & $0 \ddagger$ & 133 & 0 & 629 \\
\hline Peanut (Arachis hypogaea L.) & & - & 41 & 0 & 53 & 0 & 94 \\
\hline Poppy seed (Papaver somniferum L.) & & - & 10 & 0 & 0 & 0 & 10 \\
\hline \multicolumn{8}{|l|}{ Grain products } \\
\hline \multicolumn{8}{|l|}{ Breads } \\
\hline Whole grain flaxseed bread & & 34 & 220 & 383 & 11845 & 26 & 12474 \\
\hline Multi-grain bread & & 34 & 185 & 377 & 6163 & 19 & 6744 \\
\hline \multirow[t]{2}{*}{ Rye bread } & Dark & 46 & 122 & 172 & 13 & 14 & 320 \\
\hline & Light & 43 & 111 & 163 & 16 & 12 & 301 \\
\hline \multirow[t]{3}{*}{ Wheat bread } & Whole grain & 41 & 73 & 33 & 15 & 0 & 121 \\
\hline & Refined & 37 & 38 & 28 & 17 & 0 & 83 \\
\hline & White & 36 & 11 & 7 & 0 & 0 & 18 \\
\hline \multicolumn{8}{|l|}{ Other grain products } \\
\hline \multirow[t]{3}{*}{ Muesli (granola)§ } & Jordans, crunchy & - & 250 & 497 & 17 & 0 & 764 \\
\hline & Albert Heijn, basic & - & 120 & 210 & 13 & 0 & 343 \\
\hline & Edah, crunchy & - & 63 & 129 & 17 & 0 & 210 \\
\hline \multirow[t]{2}{*}{ Wheat (Triticum aestivum L.) } & Wholemeal & - & 140 & 38 & 31 & 0 & 210 \\
\hline & White flour & - & 18 & 9 & 0 & 0 & 27 \\
\hline \multirow[t]{2}{*}{ Rice (Oryza sativa L.) } & Whole grain, boiled & 67 & 28 & 7 & 3 & 2 & 40 \\
\hline & White,boiled & 67 & 7 & 0 & 0 & 0 & 7 \\
\hline Macaroni & White, boiled & 68 & 7 & 5 & 4 & 0 & 15 \\
\hline \multicolumn{8}{|l|}{ Vegetables and legumes } \\
\hline \multicolumn{8}{|l|}{ Brassica vegetables (Brassica oleracea L.) } \\
\hline Curly kale (cv. acephala D. C. Alef.) & & 84 & 599 & 1691 & 19 & 12 & 2321 \\
\hline Broccoli (cv. botyris L. var. italica. Plenk.) & & 87 & 972 & 315 & 38 & 0 & 1325 \\
\hline White cabbage (cv. capitale L. Alef. var. alba. D. C.) & & 89 & 212 & 568 & 8 & 0 & 787 \\
\hline Brussels sprout (cv. oleracea L. var. gemnifera $D . C$.) & & 83 & 493 & 220 & 34 & 0 & 747 \\
\hline Sauerkraut ( $c$. capitale L. Alef. var. alba. D. C.) & & 91 & 116 & 133 & 67 & 0 & 316 \\
\hline Red cabbage (cv. capitale L. Alef. var. rubra D. C.) & & 91 & 178 & 90 & 9 & 0 & 276 \\
\hline Cauliflower (cv. botrytis L. Alef. var. botyris L.) & & 92 & 124 & 58 & 4 & 0 & 185 \\
\hline Leek (Allium porrum L. var. porrum) & & 89 & 37 & 3 & 38 & 0 & 78 \\
\hline Onion (Allium cepa L. var. cepa) & & 90 & 19 & 0 & 18 & 0 & 36 \\
\hline Other vegetables & & & & & & & \\
\hline French bean (Phaseolus vulgaris L. ssp. vulgaris) & & 89 & 220 & 24 & 29 & 0 & 273 \\
\hline Sweet pepper (Capsicum annuum L.) & Green & 94 & 164 & 1 & 7 & 0 & 172 \\
\hline & Red & 91 & 106 & 1 & 7 & 0 & 113 \\
\hline Carrot (Daucus carota L.) & & 92 & 60 & 19 & 93 & 0 & 171 \\
\hline Courgette (Cucurbita pepo L. var. melopepo) & & 94 & 64 & 37 & 18 & 0 & 119 \\
\hline Spinach (Spinacea oleracea L.) & Frozen & 94 & 68 & 12 & 2 & 0 & 82 \\
\hline Cucumber (Cucumus sativus L. sspp. sativus) & & 96 & 59 & 1 & 8 & 0 & 67 \\
\hline Tomato (Lycopersicum esculentum Mill.) & & 94 & 42 & 14 & 2 & 0 & 58 \\
\hline Chicory (Chicorum intybus L. cv. foliosum) & & 95 & 6 & 25 & 17 & 0 & 48 \\
\hline Endive (Chicorum endivia L.) & & 93 & 15 & 9 & 14 & 0 & 38 \\
\hline Pea (Pisum sativum L.) & In jars & 81 & 14 & 20 & 0 & 0 & 34 \\
\hline Potato (Solanum tuberosum L.) & Nicola, boiled & 80 & 17 & 0 & 2 & 0 & 20 \\
\hline & Redstar, boiled & 76 & 8 & 0 & 1 & 0 & 10 \\
\hline Lettuce (Lactuca sativa L.) & & 96 & 5 & 4 & 8 & 0 & 16 \\
\hline Iceberg lettuce (Lactuca sativa L. cv. capitata L.) & & 95 & 2 & 0 & 9 & 0 & 11 \\
\hline Sweet corn (Zea mays L.) & In jars & 76 & 2 & 0 & 5 & 0 & 7 \\
\hline Beetroot (Beta vulgaris L. var. conditiva Alef.) & Boiled & 91 & 3 & 0 & 1 & 0 & 3 \\
\hline Mushroom (Agaricus campestris Fr.) & & 93 & 0 & 0 & 0 & 0 & 0 \\
\hline Legumes & & & & & & & \\
\hline Baked beans in tomato sauce (Phaseolus vulgaris $\mathrm{L}$.) & In jars & 71 & 21 & 9 & 8 & 0 & 37 \\
\hline Brown beans (Phaseolus vulgaris L.) & In jars & 69 & 13 & 3 & 10 & 0 & 26 \\
\hline Fruits & & & & & & & \\
\hline Apricot (Armeniaca vulgaris L.) & & 86 & 105 & 314 & 31 & 0 & 450 \\
\hline Strawberry (Fragaria $x$ ananassa Duch.) & & 91 & 117 & 212 & 5 & 0 & 334 \\
\hline Peach (Prunus persica L. Batch) & & 89 & 80 & 186 & 27 & 0 & 293 \\
\hline Pear (Pyrus communis L.) & & 84 & 155 & 34 & 4 & 0 & 193 \\
\hline Nectarine (Prunus persica L. Batch) & & 89 & 41 & 131 & 18 & 0 & 190 \\
\hline
\end{tabular}


Table 1. Continued

\begin{tabular}{|c|c|c|c|c|c|c|c|}
\hline Product & Type, processing & Moisture content $(\%)^{*}$ & LARI & PINO & SECO & MAT & Total \\
\hline \multirow[t]{2}{*}{ Raisins (Vitis euvitis vinifera L.) } & White & - & 153 & 0 & 9 & 19 & 181 \\
\hline & Blue & - & 118 & 0 & 8 & 18 & 144 \\
\hline Grapefruit (Citrus paradisi Macfad.) & Pink & 88 & 95 & 45 & 9 & 2 & 152 \\
\hline Cherries (Prunus avium L.) & & 79 & 41 & 100 & 6 & 0 & 147 \\
\hline Kiwi (Actinidia chinensis Planch.) & & 83 & 17 & 0 & 112 & 0 & 129 \\
\hline Plum (Prunus domestica L.) & & 86 & 4 & 74 & 4 & 0 & 82 \\
\hline Mandarin (Citrus reticulata Blanco) & & 86 & 57 & 21 & 3 & 1 & 81 \\
\hline \multirow[t]{2}{*}{ Olives (Olea europaea L.) } & Black & 65 & 36 & 37 & 7 & 0 & 80 \\
\hline & Green & 77 & 5 & 13 & 26 & 0 & 45 \\
\hline Orange (Citrus sinensis L. Osbeck) & & 86 & 47 & 24 & 5 & 2 & 78 \\
\hline Melon (Cucumis melo L.) & Galia & 89 & 44 & 22 & 5 & 0 & 71 \\
\hline \multirow[t]{2}{*}{ Grapes (Vitis vinifera L.) } & Blue & 80 & 52 & 0 & 4 & 5 & 60 \\
\hline & White & 83 & 25 & 4 & 10 & 3 & 42 \\
\hline Pineapple (Ananas comosus L. Merr.) & Canned & 85 & 3 & 5 & 7 & 5 & 20 \\
\hline \multirow{2}{*}{ Apple (Malus domestica Borkh.) } & Elstar & 85 & 1 & 0 & 0 & 0 & 1 \\
\hline & Jonagold & 86 & 1 & 0 & 0 & 0 & 1 \\
\hline \multicolumn{8}{|l|}{ Vegetable oils and fats } \\
\hline \multirow[t]{2}{*}{ Olive oil } & Extra-virgin & - & 4 & 243 & 0 & 0 & 248 \\
\hline & Regular & - & 5 & 101 & 0 & 0 & 106 \\
\hline Margarine & & - & 7 & 0 & 32 & 0 & 39 \\
\hline Soya oil & & - & 0 & 0 & 0 & 0 & 0 \\
\hline Sunflower oil & & - & 0 & 0 & 0 & 0 & 0 \\
\hline \multicolumn{8}{|l|}{ Other } \\
\hline Tomato paste & & 70 & 107 & 70 & 9 & 0 & 187 \\
\hline Tofu & & 80 & 61 & 61 & 18 & 0 & 140 \\
\hline Cocoa & Powder & - & 26 & 26 & 8 & 0 & 60 \\
\hline Chocolate & Plain & - & 20 & 23 & 0 & 0 & 44 \\
\hline
\end{tabular}

LARI, lariciresinol; PINO, pinoresinol; SECO, secoisolariciresinol; MAT, matairesinol.

${ }^{\star}$ Determined by freeze-drying.

$\dagger$ Not freeze-dried.

$\ddagger 0$, below detection limit: $4 \mu \mathrm{g} / 100 \mathrm{~g}$ dry weight for lariciresinol, $10 \mu \mathrm{g} / 100 \mathrm{~g}$ dry weight for pinoresinol and $6 \mu \mathrm{g} / 100 \mathrm{~g}$ dry weight for secoisolariciresinol and matairesinol; corresponding to $0.2-10 \mu \mathrm{g} / 100 \mathrm{~g}$ fresh weight, depending on the moisture content.

$\S$ Separate samples analysed instead of composite.

Ideally, the amount of lignans extracted by the analytical method should reflect the lignans that are available in the human body. So, can these ester-linked lignans be converted to enterolignans in the human body? Until now, no bioavailability studies have been performed that could answer this question. Andreasen et al. (2001) showed that human small intestine mucosa and colonic microflora contain esterase activity able to release diferrulic acids from diferrulate esters, so it is likely that these ester-linked lignans have physiological relevance. Lapierre et al. (2001) showed that $8-8^{\prime}$ diferrulate is liberated from bran lignins under alkaline conditions similar to ours, implying that our alkaline extract might contain lignans that had been incorporated in lignin structures. A rat study indeed suggested that lignins from wheat and rye bran increased the urinary excretion of enterolignans (Begum et al. 2004). However, we think that this paper probably overestimated the contribution of these lignins to the enterolignan production. Thus, alkaline extraction seems to be able to account for physiologically relevant lignans incorporated into lignins. Future human studies should, however, provide insight into the real potential of various kinds of bound lignans as enterolignan precursors.

The recovery of lignan aglycones added to control foods was regarded as satisfactory $(73-123 \%)$, except for matairesinol added to solid food (51-55\%) (Milder et al. 2004). Thus, the concentrations of matairesinol in solid foods that we report here are somewhat underestimated. The low recovery of added matairesinol is caused by its instability during alkaline extraction. However, the yield of lignans (including matairesinol) from con- trol foods was largely increased by the addition of $\mathrm{NaOH}$ during the extraction (Milder et al. 2004). Thus, alkaline extraction favours the release of matrix-bound matairesinol, which more than compensates for losses by degradation. Besides, our own and previous results show that the amount of matairesinol in foods is usually relatively low compared with that of the other enterolignan precursors. Thus, the underestimation of matairesinol will have only a small effect on estimations of the total dietary lignan content. In general, our results for matairesinol are lower than those of Mazur (Mazur \& Adlercreutz, 1998), but for some products we found higher amounts. Horn-Ross et al. (2000) detected matairesinol in only three foods. We measured two of these foods and found lower amounts of matairesinol in both.

\section{Oilseeds and nuts}

The richest source of lignans was flaxseed. Flaxseed contained mainly secoisolariciresinol $(294210 \mu \mathrm{g} / 100 \mathrm{~g})$, but pinoresinol, lariciresinol and matairesinol were also present in substantial amounts $(553-3324 \mu \mathrm{g} / 100 \mathrm{~g})$. Most of the previously reported values for secoisolariciresinol were higher than we found: $369900 \mu \mathrm{g} / 100 \mathrm{~g}$ dry weight by Mazur \& Adlercreutz (1998), 385000-670000 $\mu \mathrm{g} / 100 \mathrm{~g}$ (converted from secoisolariciresinol diglucoside) by Johnsson et al. (2000), 1261700 and $880000 \mu \mathrm{g} / 100 \mathrm{~g}$ by Liggins et al. (2000), and $495700-1006200 \mu \mathrm{g} / 100 \mathrm{~g}$ by Kraushofer \& Sontag (2002a), but lower values were also reported (e.g. $81700 \mu \mathrm{g} / 100 \mathrm{~g}$ by Obermeyer et al. 1995). In addition, the amount of matairesinol $(553 \mu \mathrm{g} / 100 \mathrm{~g})$ was relatively low compared 
Table 2. Lignan content $(\mu \mathrm{g} / 100 \mathrm{ml})$ of beverages

(Mean of duplicate analyses of composite samples)

\begin{tabular}{|c|c|c|c|c|c|c|}
\hline Product & Type, brand & LARI & PINO & SECO & MAT & Total \\
\hline \multicolumn{7}{|l|}{ Alcoholic beverages } \\
\hline \multicolumn{7}{|l|}{ Wine } \\
\hline \multirow[t]{3}{*}{ Red wine* } & Red, South Africa & $15 \cdot 9$ & $6 \cdot 3$ & $61 \cdot 3$ & $7 \cdot 8$ & $91 \cdot 3$ \\
\hline & Red, France & $16 \cdot 1$ & 9.5 & $47 \cdot 5$ & $5 \cdot 9$ & 78.9 \\
\hline & Red, France & 8.6 & 11.9 & $41 \cdot 7$ & $6 \cdot 9$ & $69 \cdot 1$ \\
\hline \multirow[t]{3}{*}{ White wine* } & White, France & 11.9 & 3.0 & $7 \cdot 6$ & 3.0 & $25 \cdot 5$ \\
\hline & White, Germany & $7 \cdot 3$ & $1 \cdot 7$ & $12 \cdot 2$ & $2 \cdot 7$ & $23 \cdot 8$ \\
\hline & White, South Africa & 4.6 & 2.5 & $5 \cdot 2$ & $3 \cdot 1$ & $15 \cdot 5$ \\
\hline \multicolumn{7}{|l|}{ Beer (lager) } \\
\hline \multirow[t]{3}{*}{ Lager $^{*}$} & Grolsch & $9 \cdot 2$ & $22 \cdot 2$ & 0.8 & $0.0 \dagger$ & $32 \cdot 2$ \\
\hline & Heineken & $9 \cdot 0$ & $21 \cdot 7$ & 1.0 & 0.0 & 31.6 \\
\hline & Bavaria & $5 \cdot 9$ & $12 \cdot 6$ & 0.0 & 0.0 & $18 \cdot 5$ \\
\hline \multicolumn{7}{|c|}{ Non-alcoholic beverages } \\
\hline \multicolumn{7}{|c|}{ Tea } \\
\hline \multirow[t]{3}{*}{ Black tea } & Ceylon* & $30 \cdot 4$ & $40 \cdot 6$ & $5 \cdot 0$ & $1 \cdot 1$ & $77 \cdot 1$ \\
\hline & English blend & $30 \cdot 8$ & 33.6 & $5 \cdot 4$ & 1.4 & $71 \cdot 2$ \\
\hline & Earl Grey* & 28.9 & $27 \cdot 0$ & $6 \cdot 2$ & 1.5 & 63.6 \\
\hline Green tea* & (with lemon flavour) & $18 \cdot 7$ & 5.7 & $12 \cdot 9$ & $2 \cdot 0$ & $39 \cdot 2$ \\
\hline \multicolumn{7}{|l|}{ Coffee } \\
\hline \multirow[t]{3}{*}{ Coffee ${ }^{*}$} & Albert Heijn, Perla Robusta & $13 \cdot 1$ & 1.5 & $16 \cdot 1$ & $0 \cdot 7$ & $31 \cdot 3$ \\
\hline & Kanis \& Gunnink & $9 \cdot 1$ & $1 \cdot 3$ & $9 \cdot 2$ & 0.0 & $19 \cdot 6$ \\
\hline & Douwe Egberts & $9 \cdot 0$ & 0.4 & $9 \cdot 4$ & 0.0 & $18 \cdot 7$ \\
\hline \multicolumn{7}{|l|}{ Juices } \\
\hline Grape juice & Blue & $6 \cdot 5$ & $3 \cdot 7$ & $10 \cdot 8$ & 3.9 & $24 \cdot 8$ \\
\hline Grape juice & White & $3 \cdot 3$ & 0.7 & $2 \cdot 5$ & 1.0 & $7 \cdot 4$ \\
\hline Tomato juice & & $9 \cdot 7$ & 9.9 & 1.6 & 0.0 & $21 \cdot 2$ \\
\hline \multirow[t]{2}{*}{ Orange juice } & Regular & $7 \cdot 0$ & $7 \cdot 5$ & $2 \cdot 7$ & 0.0 & $17 \cdot 2$ \\
\hline & With pulp & $7 \cdot 4$ & $6 \cdot 6$ & $2 \cdot 7$ & 0.0 & $16 \cdot 6$ \\
\hline Grapefruit juice & Yellow & $5 \cdot 1$ & $4 \cdot 8$ & $6 \cdot 0$ & 0.0 & $15 \cdot 9$ \\
\hline Grapefruit juice & Pink & $5 \cdot 0$ & $3 \cdot 3$ & $6 \cdot 7$ & 0.0 & $15 \cdot 0$ \\
\hline \multicolumn{7}{|l|}{ Other } \\
\hline Soya milk & & $6 \cdot 6$ & $30 \cdot 0$ & $1 \cdot 1$ & 0.0 & $37 \cdot 7$ \\
\hline Chocolate milk & Semi-skimmed & 0.9 & $1 \cdot 3$ & 0.0 & 0.0 & $2 \cdot 2$ \\
\hline Cola & & 0.0 & 0.0 & 0.0 & 0.0 & 0.0 \\
\hline
\end{tabular}

LARI, lariciresinol; PINO, pinoresinol; SECO, secoisolariciresinol; MAT, matairesinol.

* Separate samples analysed instead of composite.

$\dagger 0$, below detection limit: $0.2 \mu \mathrm{g} / 100 \mathrm{ml}$ for lariciresinol and secoisolariciresinol, $0.4 \mu \mathrm{g} / 100 \mathrm{ml}$ for pinoresinol and $0.3 \mu \mathrm{g} / 100 \mathrm{ml}$ for matairesinol.

with values previously reported: $1087 \mu \mathrm{g} / 100 \mathrm{~g}$ dry weight (Mazur \& Aldercruetz, 1998), 5680 and $9090 \mu \mathrm{g} / 100 \mathrm{~g}$ dry weight (Ziggins et al. 2000) and 700-2850 $\mu \mathrm{g} / 100 \mathrm{~g}$ dry weight (Kraushofer \& Sontag, 2002b) Both pinoresinol (Meagher et al. 1999; Qui et al. 1999) and lariciresinol (Sicilia et al. 2003) have previously been identified in flaxseed, but quantitative data were not reported.

The second highest lignan concentration was found in sesame seeds, but in this case pinoresinol was the main constituent $(29331 \mu \mathrm{g} / 100 \mathrm{~g})$, and lariciresinol was also relatively abundant $(9470 \mu \mathrm{g} / 100 \mathrm{~g})$. The presence of pinoresinol in sesame seeds has previously been described (Katsuzaki et al. 1992; Jiao et al. 1998; Kato et al. 1998); it is a precursor of the sesame lignans piperitol, sesamin and sesamolin (Jiao et al. 1998; Kato et al. 1998). The total lignan concentrations in sunflower seeds $(891 \mu \mathrm{g} / 100 \mathrm{~g})$ and cashew nuts $(629 \mu \mathrm{g} / 100 \mathrm{~g})$ were also relatively high, although the concentrations of secoisolariciresinol were low compared with those reported by Mazur \& Adlercreutz (1998). Mazur detected some matairesinol ( $4 \mu \mathrm{g} / 100 \mathrm{~g}$ dry weight) in cashew nuts, which we did not find. In poppy seeds, we detected only lariciresinol $(10 \mu \mathrm{g} / 100 \mathrm{~g})$, whereas Mazur \& Adlercreutz (1998) also reported the presence of secoisolariciresinol $(14 \mu \mathrm{g} / 100 \mathrm{~g}$ dry weight $)$ and matairesinol ( $12 \mu \mathrm{g} / 100 \mathrm{~g}$ dry weight $)$.

\section{Grain products}

Both wholegrain flaxseed bread and multigrain bread had a high lignan content (12500 and $6700 \mu \mathrm{g} / 100 \mathrm{~g})$, which can be attributed to the flaxseed present in these breads. For breads without flaxseed, the highest lignan concentration was found in rye bread, but the levels of secoisolariciresinol and matairesinol were approximately two- to three-fold lower than reported for Finnish rye (Nilsson et al. 1997a) and rye bread (Juntunen et al. 2000). For wheat bread, wheat, and rice, the lignan content decreased with the level of refinement. This is in agreement with previous findings (for rye) that lignans are mainly present in the short and bran of grain, which are removed during the refining of grain products (Nilsson et al. 1997b).

\section{Vegetables and legumes}

Brassica vegetables (cabbages, Brussel sprouts, kale) contained unexpectedly high levels of lignans $(185-2321 \mu \mathrm{g} / 100 \mathrm{~g})$, mainly due to pinoresinol and lariciresinol. The amount of pinoresinol plus lariciresinol in Brassica vegetables was on average forty-five times higher than that of secoisolariciresinol 
plus matairesinol. Our results for secoisolariciresinol in broccoli, cabbage and Brussel sprouts agree well with those of Mazur, but in broccoli and Brussel sprouts, they again report the presence of some matairesinol. Horn-Ross et al. (2000) reported a similar amount of secoisolariciresinol as we found in Brussel sprouts, but they did not detect secoisolariciresinol or matairesinol in broccoli.

Allium vegetables also contained substantial amounts of lignans $(36-536 \mu \mathrm{g} / 100 \mathrm{~g})$. The concentration of secoisolariciresinol in garlic reported by Horn-Ross et al. (2000) was approximately half of what we found, but they reported $38 \mu \mathrm{g} / 100 \mathrm{~g}$ matairesinol, which we did not detect in garlic. The amount of secoisolariciresinol in garlic reported by Mazur \& Adlercreutz (1998) was approximately twice as high as we found, and they reported only trace amounts of matairesinol. For leeks, the concentration of secoisolariciresinol reported by Valsta et al. (2003) was approximately three times lower than we found, and they also did not detect matairesinol.

French beans $(273 \mu \mathrm{g} / 100 \mathrm{~g})$, sweet peppers (green: $172 \mu \mathrm{g} /$ $100 \mathrm{~g}$; red: $113 \mu \mathrm{g} / 100 \mathrm{~g})$, carrots $(171 \mu \mathrm{g} / 100 \mathrm{~g})$ and courgettes $(119 \mu \mathrm{g} / 100 \mathrm{~g})$ also had relatively high lignan concentrations. For all other vegetables, the total lignan concentrations were below $100 \mu \mathrm{g} / 100 \mathrm{~g}$.

\section{Fruits}

Lignan values ranged from 0 for banana to $450 \mu \mathrm{g} / 100 \mathrm{~g}$ for apricot. Valsta et al. (2003) reported the lignan contents of six fruits, of which we also measured five. The concentrations of secoisolariciresinol and matairesinol in pear, grapefruit, olive and kiwi were somewhat higher than we found, whereas we found a higher amount of secoisolariciresinol in grapes. Horn-Ross et al. (2000) were able to detect secoisolariciresinol and matairesinol in only a few dried fruits (apricots, prunes, raisins) and in peaches. The concentrations they reported for peaches agree well with ours.

Strawberries had a total lignan concentration of $334 \mu \mathrm{g} / 100 \mathrm{~g}$. Mazur et al. (2000) found relatively high levels of secoisolariciresinol in berries. Although we did not find a large amount of secoisolariciresinol in strawberries, the amounts of lariciresinol and pinoresinol were relatively large.

Raisins (white and blue) were one of the few products in which we detected matairesinol (19 and $18 \mu \mathrm{g} / 100 \mathrm{~g}$, respectively). However, the amount of matairesinol in raisins was low compared with that of lariciresinol ( 153 and $118 \mu \mathrm{g} / 100 \mathrm{~g}$ for white and blue raisins respectively). Horn-Ross et al. (2000) reported a higher concentration of matairesinol in raisins $(52 \mu \mathrm{g} / 100 \mathrm{~g})$ and only trace amounts of secoisolariciresinol.

The lignan concentration in apple was only $1 \mu \mathrm{g} / 100 \mathrm{~g}$, which is interesting because apple is an important source of other polyphenols such as flavonoids (Hertog et al. 1992; Arts et al. 2000). In addition, Mazur \& Adlercreutz (1998) and Horn-Ross et al. (2000) reported only trace amounts of lignans in apple.

\section{Vegetable oils and fats}

The amount of pinoresinol in extra-virgin olive oil $(243 \mu \mathrm{g} / 100 \mathrm{~g})$ was higher than that in regular olive oil $(101 \mu \mathrm{g} / 100 \mathrm{~g})$. This is in agreement with the data published by Owen et al. (2000), who found low levels of lignans in refined olive oil but lignan levels of $65-10000 \mu \mathrm{g} / 100 \mathrm{~g}$ in extra-virgin oils. These lignans were identified as pinoresinol, 1-acetoxypinoresinol and 1-hydroxypinor- esinol. The amount of pinoresinol that we found in extra-virgin oil (of unknown origin), was much lower than that found in Spanish extra-virgin olive oils (range 2000-4500 $\mu \mathrm{g} / 100 \mathrm{~g}$; Brenes et al. $2002 b$ ). Possibly, extra-virgin olive oil in the Netherlands is more refined than in Spain. Margarine was also selected for analysis, since it contains vegetable fats. The lignan concentration in margarine was $39 \mu \mathrm{g} / 100 \mathrm{~g}$; it contained mainly secoisolariciresinol. No lignans were found in soya and sunflower oil.

\section{Other solid foods}

The concentration of lignans in tomato paste was higher than that of tomato, which can of course be explained by the concentration step that takes place during manufacturing. It also shows that lignans can (at least partially) survive the production process of tomato paste.

Soya products have primarily been included in phytoestrogen databases because of the high amount of isoflavones in soya, but soyabeans were additionally shown to contain a relatively high amount of secoisolariciresinol (13-273 $\mu \mathrm{g} / 100 \mathrm{~g}$; Mazur et al. 1998a). In tofu, however, we found only $18 \mu \mathrm{g} / 100 \mathrm{~g}$. Horn-Ross et al. (2000) also detected a relatively high amount of secoisolariciresinol $(140 \mu \mathrm{g} / 100 \mathrm{~g})$ in soyabeans, but did not detect any secoisolariciresinol or matairesinol in tofu. This is in agreement with our result, because of their high limit of detection of $25 \mu \mathrm{g} / 100 \mathrm{~g}$.

Cocoa powder and plain chocolate contained a substantial amount of lignans, although the amount of secoisolariciresinol was approximately $50 \%$ lower than that reported by Valsta et al. (2003). Similar to our findings, they did not detect any matairesinol.

\section{Alcoholic beverages}

Wine, especially red wine, is an important source of several polyphenols (Manach et al. 2004), and we found that it also contained a relatively high concentration of lignans. Red wine contained on average $80 \mu \mathrm{g} / 100 \mathrm{ml}$, whereas white wine contained $22 \mu \mathrm{g} / 100 \mathrm{ml}$. Secoisolariciresinol was the most abundant lignan in wine, except in one white wine in which lariciresinol was more abundant. Our results for secoisolariciresinol and matairesinol were slightly lower than those reported by Mazur (1998). Nurmi et al. (2003) analysed lignans in wines using HPLC with coulometric electrode array detection. Besides secoisolariciresinol and matairesinol, they also included other plant lignans. Their results for secoisolariciresinol, matairesinol and lariciresinol were slightly lower than ours. They could not exactly quantify pinoresinol but reported that the amount was similar to that of lariciresinol, which is also in agreement with our results.

On average, lager beer contained more lignans $(27 \mu \mathrm{g} / 100 \mathrm{ml})$ than white wine but less than red wine. Beer contained mainly pinoresinol and lariciresinol, and only a little secoisolariciresinol.

\section{Non-alcoholic beverages}

For the non-alcoholic beverages, the highest amount of lignans was found in tea, a product that is a rich source of various other polyphenols (Manach et al. 2004). The amounts of lignans in the three blends of black tea that were analysed were comparable $(64-77 \mu \mathrm{g} /$ $100 \mathrm{ml})$, but the amount of lignans in green tea was lower $(39 \mu \mathrm{g} /$ $100 \mathrm{ml})$. Mazur et al. (1998b) expressed the lignan values of tea infusions on a $\mathrm{mg} / \mathrm{kg}$ tea leaves basis. If we convert our tea infusion values to $\mathrm{mg} / \mathrm{kg}$ tea leaves, our results for secoisolariciresinol are 
Table 3. Comparison of lignan concentrations $(\mu \mathrm{g} / 100 \mathrm{~g})$ in raw and cooked vegetables

(Mean of duplicate analyses)

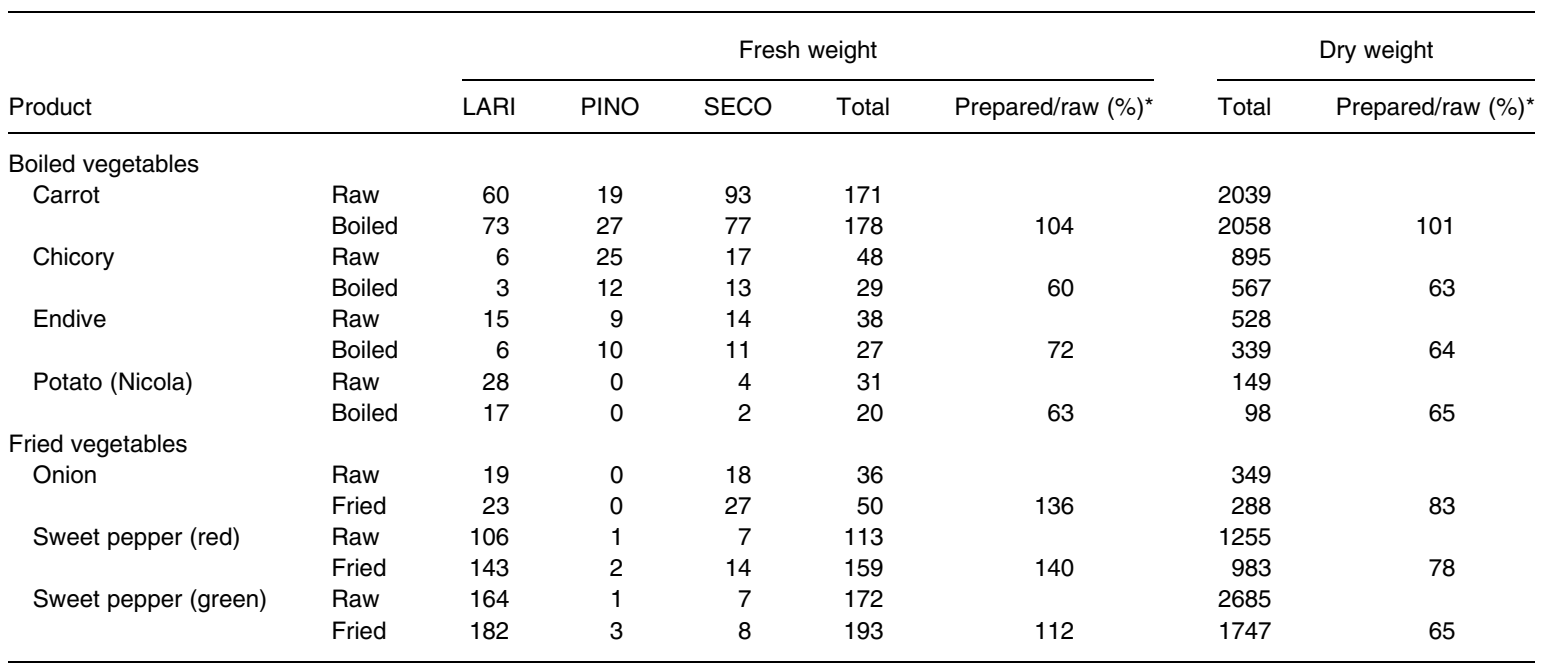

LARI, lariciresinol; PINO, pinoresinol; SECO, secoisolariciresinol. O, below detection limit: $4 \mu \mathrm{g}$ dry weight lariciresinol, $10 \mu \mathrm{g} / 100 \mathrm{~g}$ dry weight for pinoresinol, $6 \mu \mathrm{g} / 100 \mathrm{~g}$ dry weight for secoisolariciresinol and matairesinol.

$* \%=$ lignan concentration in boiled or fried vegetable compared with raw vegetable.

approximately $1 \cdot 5-2 \cdot 5$-fold lower than those of Mazur and co-workers, whereas the results for matairesinol are similar. For the preparation of their tea infusion, both the amount of tea leaves (per ml water) and the extraction time used by Mazur and co-workers were twice that of our method. Since we found lower values of secoisolariciresinol in both black and green tea, this might indicate that a higher proportion of secoisolariciresinol could be extracted with longer extraction times. However, our aim was to analyse tea infusion as it is commonly consumed in the Netherlands.

The amount of lignans in coffee was lower than that in tea $(19-31 \mu \mathrm{g} / 100 \mathrm{ml})$, which is consistent with the results of Mazur et al. (1998b).

The total lignan concentration in juices was $7-25 \mu \mathrm{g} / 100 \mathrm{ml}$. As for red wine, and blue grapes, the amount of lignans was higher in blue grape juice than in white grape juice. In general, therefore, the lignan content of blue grapes seems higher than that of white grapes, although the amount of lignans in white raisins was higher than in blue raisins. We did not find a difference between orange juice with and without pulp. We hypothesised that this could be caused by the fact that lignans were not released from the pulp. We thus also analysed juice with pulp with the method for solid foods (including alkaline extraction). This resulted in slightly lower lignan concentrations compared with the analysis without alkaline extraction (results not shown). Thus, the pulp in orange juice did not contain a measurable amount of lignans.

Soya milk contained $38 \mu \mathrm{g}$ lignans $/ 100 \mathrm{ml}$, mainly pinoresinol and lariciresinol. We measured only $1 \mu \mathrm{g} / 100 \mathrm{ml}$ of secoisolariciresinol in soya milk, whereas Adlercreutz et al. (2000) found $10-20 \mu \mathrm{g} / 100 \mathrm{~g}$ in soya milk and drinks. Horn-Ross et al. (2000) reported $32 \mu \mathrm{g} / 100 \mathrm{ml}$ secoisolariciresinol in soya milk.

\section{Effect of cooking of vegetables}

Lignan values in boiled vegetables were on average $25 \%$ lower than those in raw vegetables (Table 3), whereas after frying, lignan concentrations were on average $30 \%$ higher. The increased lignan concentrations after frying can be explained mainly by the decreased moisture content of the fried foods. On a dry weight basis, the amount of lignans after frying decreased by $25 \%$, comparable to what we saw for boiling. The vegetables were fried in margarine, which we have shown also to contain some lignans. However, we calculated that the maximum contribution from lignans in the margarine was less than $1 \%$.

To our knowledge, effects of food preparation on lignan content have only been reported for baking bread, thermal treatments of olive oil, and roasting of pumpkin seeds. Muir \& Westcott (2000) reported that secoisolariciresinol diglucoside (purified or as flaxseed), added to wheat flour before the preparation of bread, was stable in the bread making process. Besides, they found that secoisolariciresinol diglucoside could withstand the higher temperatures in the core during baking. Brenes et al. (2002a) found that microwave heating of olive oil for $10 \mathrm{~min}$ did not change the amount of lignans, including pinoresinol. Even after $25 \mathrm{~h}$ (simulated) frying at $180^{\circ} \mathrm{C}$, only $20-50 \%$ of the lignans were lost, whereas other phenolic compounds were almost completely destroyed. When olive oil was boiled with water (at $\mathrm{pH} \mathrm{4-6)} \mathrm{for} 30 \mathrm{~min}$, a large proportion of lignans leached into the water phase, but the total decrease in the lignan concentration was only $30 \%$, irrespective of the $\mathrm{pH}$. Murkovic et al. (2004) reported that secoisolariciresinol in pumpkin seeds was completely destroyed after $20 \mathrm{~min}$ of roasting. Thus, a further evaluation of the effects of food processing might increase the reliability of lignan intake estimations.

In summary, almost all of the 109 measured products contained lignans, and in most cases the amount of lariciresinol and pinoresinol was larger than that of secoisolariciresinol and matairesinol. Thus, available databases largely underestimate the amount of enterolignan precursors in foods. The database reported here will enable a more comprehensive evaluation of the health effects of lignan intake. 


\section{Acknowledgements}

Lariciresinol and pinoresinol were kindly provided by Dr Ozawa (Rakuno Gakuen University, Japan), Dr Deyama (Yomeishu Seizo Co. Ltd, Japan) and Dr Nishibe (University of Hokkaido, Japan). Internal standards secoisolariciresinol- $\mathrm{d}_{8}$ and matairesinol- $\mathrm{d}_{6}$ were kindly provided by Dr K. Wähälä (University of Helsinki, Finland). This work was financed by the Netherlands Organisation for Health Research and Development (Program Nutrition: Health, Safety and Sustainability; project number 014-12-014)

\section{References}

Adlercreutz H \& Mazur W (1997) Phyto-oestrogens and Western diseases. Ann Med 29, 95-120.

Adlercreutz H, Mazur W, Bartels P, et al. (2000) Phytoestrogens and prostate disease. J Nutr 130, 658S-659S.

Adlercreutz H, Mousavi Y, Clark J, Hockerstedt K, Hamalainen E, Wähälä K, Makela T \& Hase T (1992) Dietary phytoestrogens and cancer - in vitro and in vivo studies. J Steroid Biochem Mol Biol 41, 331-337.

Andreasen MF, Kroon PA, Williamson G \& Garcia-Conesa MT (2001) Intestinal release and uptake of phenolic antioxidant diferulic acids. Free Radical Biol Med 31, 304-314.

Arts ICW \& Hollman PCH (2005) Polyphenols and disease risk in epidemiological studies. Am J Clin Nutr 81 Suppl., 5317-5325.

Arts ICW, van de Putte B \& Hollman PCH (2000) Catechin contents of foods commonly consumed in The Netherlands. 1. Fruits, vegetables, staple foods, and processed foods. J Agric Food Chem 48, 1746-1751.

Begum AN, Nicolle C, Mila I, et al. (2004) Dietary lignins are precursors of mammalian lignans in rats. $J$ Nutr 134, 120-127.

Brenes M, Garcia A, Dobarganes MC, Velasco J \& Romero C (2002a) Influence of thermal treatments simulating cooking processes on the polyphenol content in virgin olive oil. J Agric Food Chem 50, 5962-5967.

Brenes M, Garcia A, Rios JJ, Garcia P \& Garrido A (2002b) Use of 1-acetoxypinoresinol to authenticate Picual olive oils. Int J Food Sci Tech 37, 615-625.

Dai Q, Franke AA, Jin F, Shu XO, Hebert JR, Custer LJ, Cheng JR, Gan YT \& Zheng W (2002) Urinary excretion of phytoestrogens and risk of breast cancer among Chinese women in Shanghai. Cancer Epidemiol Biomarkers Prev 11, 815-821.

Den Tonkelaar I, Keinan-Boker L, Van t Veer P, Arts CJM, Adlercreutz H, Thijssen JHH \& Peeters PHM (2001) Urinary phytoestrogens and postmenopausal breast cancer risk. Cancer Epidemiol Biomarkers Prev 10, 223-228.

Ford JD, Huang KS, Wang HB, Davin LB \& Lewis NG (2001) Biosynthetic pathway to the cancer chemopreventive secoisolariciresinol diglucoside-hydroxymethyl glutaryl ester-linked lignan oligomers in flax (Linum usitatissimum) seed. $J$ Nat Prod 64, $1388-1397$.

Grace PB, Taylor JI, Low YL, et al. (2004) Phytoestrogen concentrations in serum and spot urine as biomarkers for dietary phytoestrogen intake and their relation to breast cancer risk in European prospective investigation of cancer and nutrition-norfolk. Cancer Epidemiol Biomarkers Prev 13, 698-708.

Heinonen S, Nurmi T, Liukkonen K, Poutanen K, Wähälä K, Deyama T, Nishibe S \& Adlercreutz H (2001) In vitro metabolism of plant lignans: new precursors of mammalian lignans enterolactone and enterodiol. $J$ Agric Food Chem 49, 3178-3186.

Hertog MGL, Hollman PCH \& Katan MB (1992) Content of potentially anticarcinogenic flavanoids of 28 vegetables and 9 fruits commonly consumed in the Netherlands. J Agric Food Chem 40, $2379-2383$.
Horn-Ross PL, Barnes S, Lee M, Coward L, Mandel JE, Koo J, John EM \& Smith M (2000) Assessing phytoestrogen exposure in epidemiologic studies: development of a database (United States). Cancer Causes Control 11, 289-298.

Horn-Ross PL, Hoggatt KJ \& Lee MM (2002a) Phytoestrogens and thyroid cancer risk: the San Francisco Bay Area thyroid cancer study. Cancer Epidemiol Biomarkers Prev 11, 43-49.

Horn-Ross PL, Hoggatt KJ, West DW, et al. (2002b) Recent diet and breast cancer risk: the California teachers study (USA). Cancer Causes Control 13, 407-415.

Horn-Ross PL, John EM, Canchola AJ, Stewart SL \& Lee MM (2003) Phytoestrogen intake and endometrial cancer risk. J Natl Cancer Inst 95, 1158-1164.

Horn-Ross PL, John EM, Lee M, et al. (2001) Phytoestrogen consumption and breast cancer risk in a multiethnic population - the Bay Area Breast Cancer Study. Am J Epidemiol 154, 434-441.

Hulshof KF \& Van Staveren WA (1991) The Dutch National Food Consumption Survey: design, methods and first results. Food Policy 16, $257-260$.

Hulten K, Winkvist A, Lenner P, Johansson R, Adlercreutz H \& Hallmans G (2002) An incident case-referent study on plasma enterolactone and breast cancer risk. Eur J Nutr 41, 168-176.

Ingram D, Sanders K, Kolybaba M \& Lopez D (1997) Case-control study of phyto-oestrogens and breast cancer. Lancet 350, 990-994.

Jiao Y, Davin LB \& Lewis NG (1998) Furanofuran lignan metabolism as a function of seed maturation in Sesamum indicum: methylenedioxy bridge formation. Phytochemistry 49, 387-394.

Johnsson P, Kamal Eldin A, Lundgren LN \& Aman P (2000) HPLC method for analysis of secoisolariciresinol diglucoside in flaxseeds. $J$ Agric Food Chem 48, 5216-5219.

Juntunen KS, Mazur WM, Liukkonen KH, Uehara M, Poutanen KS, Adlercreutz HCT \& Mykkanen HM (2000) Consumption of wholemeal rye bread increases serum concentrations and urinary excretion of enterolactone compared with consumption of white wheat bread in healthy Finnish men and women. Br J Nutr 84, 839-846.

Kato MJ, Chu A, Davin LB \& Lewis NG (1998) Biosynthesis of antioxidant lignans in Sesamum indicum seeds. Phytochemistry 47, $583-591$

Katsuzaki H, Kawasumi M, Kawakishi S \& Osawa T (1992) Structure of novel antioxidative lignan glucosides isolated from sesame seed. Biosci Biotechn Biochem 56, 2087-2088.

Keinan Boker L, Van der Schouw YT, De Kleijn MJ, Jacques PF, Grobbee DE \& Peeters PH (2002) Intake of dietary phytoestrogens by Dutch women. J Nutr 132, 1319-1328.

Kraushofer T \& Sontag G (2002a) Determination of some phenolic compounds in flax seed and nettle roots by HPLC with coulometric electrode array detection. Eur Food Res. Technol. 215, 529-533.

Kraushofer T \& Sontag G (2002b) Determination of matairesinol in flax seed by HPLC with coulometric electrode array detection. J. Chromatogr B Biomed Sci Appl 777, 61-66.

Lapierre C, Pollet B, Ralet MC \& Saulnier L (2001) The phenolic fraction of maize bran: evidence for lignin-heteroxylan association. Phytochemistry 57, 765-772.

Liggins J, Grimwood R \& Bingham SA (2000) Extraction and quantification of lignan phytoestrogens in food and human samples. Anal Biochem 287, 102-109.

Linseisen J, Piller R, Hermann S \& Chang-Claude J (2004) Dietary phytoestrogen intake and premenopausal breast cancer risk in a German case-control study. Int J Cancer 110, 284-290.

McCann SE, Freudenheim JL, Marshall JR \& Graham S (2003) Risk of human ovarian cancer is related to dietary intake of selected nutrients, phytochemicals and food groups. J Nutr 133, 1937-1942.

McCann SE, Moysich KB, Freudenheim JL, Ambrosone CB \& Shields PG (2002) The risk of breast cancer associated with dietary lignans differs by CYP17 genotype in women. J Nutr 132, 3036-3041.

Manach C, Scalbert A, Morand C, Remesy C \& Jimenez L (2004) Polyphenols: food sources and bioavailability. Am J Clin Nutr 79, 727-747. 
Mazur W (1998) Phytoestrogen content in foods. Baillières Clin Endocrinol Metab 12, 729-742.

Mazur W \& Adlercreutz H (1998) Naturally occurring oestrogens in food. Pure Appl Chem 70, 1759-1776.

Mazur W \& Adlercreutz H (2000) Overview of naturally occurring endocrine-active substances in the human diet in relation to human health. Nutrition 16, 654-658.

Mazur WM, Duke JA, Wähälä K, Rasku S \& Adlercreutz H (1998a) Isoflavonoids and lignans in legumes: nutritional and health aspects in humans. J Nutr Biochem 9, 193-200.

Mazur W, Fotsis T, Wähälä K, Ojala S, Salakka A \& Adlercreutz H (1996) Isotope dilution gas chromatographic-mass spectrometric method for the determination of isoflavonoids, coumestrol, and lignans in food samples. Anal Biochem 233, 169-180.

Mazur WM, Uehara M, Wähälä K \& Adlercreutz H (2000) Phyto-oestrogen content of berries, and plasma concentrations and urinary excretion of enterolactone after a single strawberry-meal in human subjects. $\mathrm{Br} J$ Nutr 83, 381-387.

Mazur WM, Wähälä K, Rasku S, Salakka A, Hase T \& Adlercreutz H (1998b) Lignan and isoflavonoid concentrations in tea and coffee. $\mathrm{Br}$ J Nutr 79, 37-45.

Meagher LP \& Beecher GR (2000) Assessment of data on the lignan content of foods. J Food Compos Anal 13, 935-947.

Meagher LP, Beecher GR, Flanagan VP \& Li BW (1999) Isolation and characterization of the lignans, isolariciresinol and pinoresinol, in flaxseed meal. J Agric Food Chem 47, 3173-3180.

Milder IEJ, Arts ICW, Venema DP, Lasaroms JJP, Wähälä K \& Holllman PCH (2004) Optimization of a liquid chromatography-tandem mass spectrometry method for quantification of the plant lignans secoisolariciresinol, matairesinol, lariciresinol and pinoresinol in foods. J Agric Food Chem 52, 4643-4651.

Muir AD \& Westcott ND (2000) Quantitation of the lignan secoisolariciresinol diglucoside in baked goods containing flax seed or flax meal. $J$ Agric Food Chem 48, 4048-4052.

Murkovic M, Piironen V, Lampi AM, Kraushofer T \& Sontag G (2004) Changes in chemical composition of pumpkin seeds during the roasting process for production of pumpkin seed oil. 1. Non-volatile compounds. Food Chem 84, 359-365.

Nilsson M, Aman P, Harkonen H, Hallmans G, Knudsen KEE, Mazur W \& Adlercreutz H (1997a) Nutrient and lignan content, dough properties and baking performance of rye samples used in Scandinavia. Acta Agric Scand Sect B Soil Plant Sci 47, 26-34.
Nilsson M, Aman P, Harkonen H, Hallmans G, Knudsen K, Mazur W \& Adlercreutz H (1997b) Content of nutrients and lignans in roller milled fractions of rye. J Sci Food Agric 73, 143-148.

Nurmi T, Heinonen S, Mazur W, Deyama T, Nishibe S \& Adlercreutz H (2003) Lignans in selected wines. Food Chem 83, 303-309.

Obermeyer WR, Musser SM, Betz JM, Casey RE, Pohland AE \& Page SW (1995) Chemical studies of phytoestrogens and related compounds in dietary supplements: flax and chaparral. Proc Soc Exp Biol Med 208, 6-12.

Owen RW, Mier W, Giacosa A, Hull WE, Spiegelhalder B \& Bartsch H (2000) Identification of lignans as major components in the phenolic fraction of olive oil. Clin Chem 46, 976-988.

Pietinen P, Stumpf K, Mannisto S, Kataja V, Uusitupa M \& Adlercreutz H (2001) Serum enterolactone and risk of breast cancer: a case-control study in Eastern Finland. Cancer Epidemiol Biomarkers Prev 10, 339-344

Qui SX, Lu ZZ, Luyengi L, Lee SK, Pezzuto JM, Farnsworth NR, Thompson LU \& Fong HHS (1999) Isolation and characterization of flaxseed (Linum usitatissimum) constituents. Pharm Biol 37, 1-7.

Raffaelli B, Hoikkala A, Leppala E \& Wähälä K (2002) Enterolignans. J Chromatogr B Biomed Sci Appl 777, 29-43.

Sicilia T, Niemeyer HB, Honig DM \& Metzler M (2003) Identification and stereochemical characterization of lignans in flaxseed and pumpkin seeds. J Agric Food Chem 51, 1181-1188.

Valsta LM, Kilkkinen A, Mazur W, Nurmi T, Lampi AM, Ovaskainen ML, Korhonen T, Adlercreutz H \& Pietinen P (2003) Phyto-oestrogen database of foods and average intake in Finland. Br J Nutr 89, S31-S38.

Van Dooren-Flipsen MMH, Boeijen I, Van Klaveren JD \& Van Donkersgoed G (1995) Conversie van consumeerbare voedingsmiddelen naar primaire agrarische producten [in Dutch]. Report-95.17. Wageningen, The Netherlands: RIKILT.

Vanharanta M, Voutilainen S, Lakka TA, van der Lee M, Adlercreutz H \& Salonen JT (1999) Risk of acute coronary events according to serum concentrations of enterolactone: a prospective population-based casecontrol study. Lancet 354, 2112-2115.

Vanharanta M, Voutilainen S, Rissanen TH, Adlercreutz H \& Salonen JT (2003) Risk of cardiovascular disease-related and all-cause death according to serum concentrations of enterolactone: Kuopio ischaemic heart disease risk factor study. Arch Intern Med 163, 1099-1104.

Voedingscentrum (1998) Zo eet Nederland; Resultaten van de Voedselconsumptiepeiling 1997-1998 [in Dutch]. The Hague, The Netherlands: Voedingscentrum. 